\title{
Solar Power in the Island Nation, Mauritius
}

\author{
Dhirajsing Rughoo* \\ Department of Electrical and Electronic Engineering, Universite Des mascareignes. Avenue de la \\ Concorde, Beau Bassin-Rose Hill, Mauritius.
}

\begin{abstract}
The challenges to integrating a greater share of renewable energy, more specifically solar energy into the power grid in tropical islands are that these islands have a complex microclimate, high humidity and high cloud coverage. Because of this, the power output from solar photovoltaic (SPV) plants is severely affected. In this manuscript, the results of a study carried out on the performance of a 15.2 MW solar photovoltaic (SPV) plant in the island nation Mauritius is presented. The net annual yield was $22162 \mathrm{MWh}$ and has avoided 22162 metric $\mathrm{t}$ of $\mathrm{CO}_{2}$ emission into the atmosphere. An attempt is also made to develop a model to forecast the power that can be generated from the SPV plants at that location. The grid operator, the national Central Electricity Board (CEB) needs to know a priori, the energy mix for the subsequent few days so that the level of operation of fossil fuel fired thermal plants can be tuned accordingly to minimize the environment pollution of this pristine island.
\end{abstract}

Keywords: Atmospheric pollution, power management, renewable energy, solar photovoltaic plant

\section{Introduction}

The islands face serious problems in meeting the increasing power demand of its citizens. Most of these islands are dependent on transported fossil fuels for generating power. In 2017 , about $79 \%$ of electricity consumed on the island was generated from imported coal and oil [1]. With increasing concern over the environmental effects of burning fossil fuels, the call for a more sustainable resource base has never been louder. This explains why most of the islands are slowly moving towards seeking sustainable energy production and reduction of greenhouse gas (GHG) emission [2-5]. Hence, renewable energy sources (RES) play a very important role in distributed power generation. Practically, a sudden or a complete departure from fossil fuels is not possible and hence, the RES remains as a subsidiary for the conventional energy sources that are mainly powered by fossil fuels. The power demand at a location will be a mix of power from many resources which can be represented as Equation (1)

$$
\mathrm{P}=\mathrm{aP} \mathrm{P}_{\mathrm{F}}+\mathrm{bP}+\mathrm{cP}+\mathrm{PP}_{\mathrm{O}}
$$

*Corresponding author: $\underline{\text { drughoo@udm.ac.mu }}$ 
where $\mathrm{P}_{\mathrm{F}}, \mathrm{P}_{\mathrm{S}}, \mathrm{P}_{\mathrm{W}}$ and $\mathrm{P}_{\mathrm{O}}$ are the installed capacities of fossil fuel fired plants, solar installations, wind parks and other sources like biogas, hydro, CCGT or imports, respectively. a, b, c and d are the percentage utilizations that are needed to meet the power demand, $\mathrm{P}$. When $\mathrm{b}$ and $\mathrm{c}$ are high, a and $\mathrm{d}$ could be reduced, decreasing the polluting gases. It is quite complex to find ways to satisfy the energy needs without wastage. Yield from SPV plants is dependent on environmental variables. Unless the solar plants are partially shut down, the generation from them cannot be controlled when there is excess electricity generation. Hence, having a reliable model to predict yield is very essential for energy resource management. Attempts have been made to develop empirical models for predicting power yield from solar plants $[6,7]$. There are several tools to predict the power output of smaller roof-top SPV systems based on the average historical solar radiation input as it is important to arrive at a forecast model which can be conveniently used by the end users also. Net-metering mechanism at household level being the recent trend in developing countries. However, for a larger power generating SPV plants which are integrated into the grid as dispatchable sources, it is better to adopt a model which involves the major parameters which cause attenuation of solar radiation at upper atmosphere at a given location and solar power output at a location. This model must deliver the yield of an SPV system using the forecast data available on public domain and must be simple to use by the power vendors.

Mauritius is an island in the Indian Ocean located around latitude $20.35^{\circ} \mathrm{S}$ and longitude $57.55^{\circ} \mathrm{E}$. Being a small island, Mauritius accommodates different micro-climates in terms of precipitation and temperature. In this paper, we establish an empirical relationship between yield and atmospheric conditions based on the data from a 15.2 MW SPV plant with polycrystalline silicon PV modules installed in a tropical island nation Mauritius. The power production patterns during various atmospheric conditions are studied. A multivariate regression is used to obtain the best fit expression. This will enable power producers to predict, in advance, the expected yield under different climatic conditions. With such predictions, production of electricity from different resources such as coal and diesel could be minimized and consequently the emissions of greenhouse gases could be reduced.

\section{Experimental details}

\subsection{Description of the SPV plant}

The SPV plant (Figure 1) is located in Bambous village in the western quartile of the Island of Mauritius. A small tropical island in the Indian ocean, Mauritius has only two seasons: summer and winter. The former runs from November to April whilst winter is from May to October. January is the hottest month with an average temperature of $26^{\circ} \mathrm{C}$. There are small differences in temperature between the two seasons. 


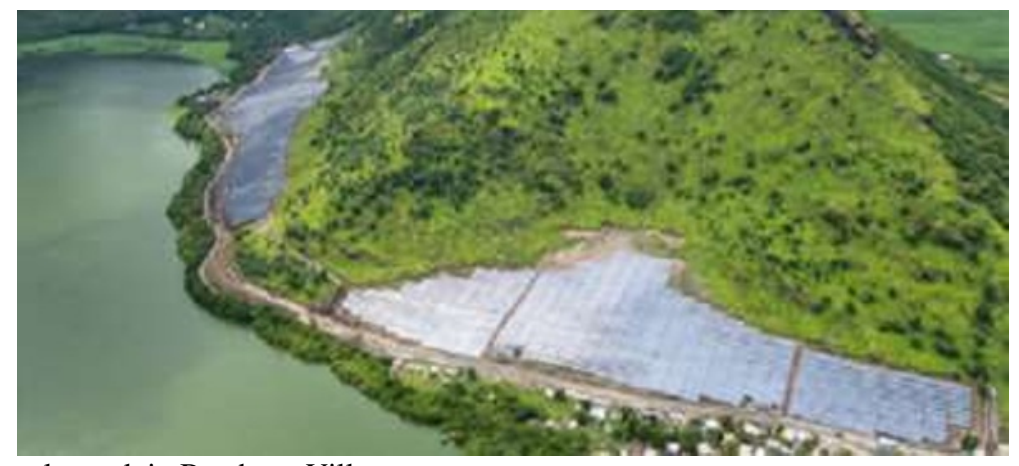

Fig. 1. The solar park in Bambous Village.

This SPV plant is the first high scale solar park in Mauritius with $15.2 \mathrm{MW}$ capacity and is situated at a longitude of 57.4147 East and latitude 20.2619 South over 34 ha in the western district of Rivière Noire. The plant includes 60800 polycrystalline solar panels. Each panel is of efficiency $15.3 \%, 1640 \mathrm{~mm}^{2} \times 992 \mathrm{~mm}^{2}$ in size and has 60 cells connected in series with power output of $250 \mathrm{w}$. Open circuit voltage is $37.8 \mathrm{~V}$ while short circuit current is $8.9 \mathrm{~A}$. Maximum power voltage is $30.5 \mathrm{~V}$ and maximum current is $8.2 \mathrm{~A}$. An inverter of $1 \mathrm{MW}$ has eight combiner boxes connected in series. Each combiner boxes may contain 20 to 23 strings, which are connected in parallel. The Berlin-based Skytron Energy Bambous solar plant feeds into country's $66 \mathrm{kV}$ grid and meets all the challenges that an island grid with its inherent imbalances typically entails.

The SPV modules are oriented towards the North with an inclination of $20^{\circ}$, which is the latitude of the location. A remote monitoring system records the real-time data. The global horizontal irradiance (GHI), power output and module temperature and humidity, data are collected at an interval of $30 \mathrm{~min}$. The cloud cover factor is collected every four hours. GHI is measured at high frequency sampling rate of one minute using ISO 9060 secondary standard broadband EKO MS 802 pyranometers. Ambient temperature is measured with a calibrated platinum thermistor Pt100.

\section{Results and discussions}

\subsection{Performance of the SPV System}

The monthly yield of the SPV system during May 2017 to April 2018 is shown in Figure 2. The highest monthly yield was in October (2 $325 \mathrm{MWh})$ and the least in August (1 $379 \mathrm{MWh}$ ) corresponding to summer and winter months, respectively. The net annual yield during this period was $22162 \mathrm{MWh}$. Since in Mauritius, power generation is by the combustion of both coal and diesel by almost equal amounts, the SPV plant has avoided over 22162 metric $\mathrm{t}$ of $\mathrm{CO}_{2}$ emission into the atmosphere in $1 \mathrm{yr}$ assuming an average of $1.0 \mathrm{~kg} \mathrm{kWh}^{-1}$ of $\mathrm{CO}_{2}$ emission from both coal and diesel-fired thermal plants [8, 9].

Capacity utilization factor (CUF) is an indicator of the overall performance of the SPV system. CUF of a SPV system is the ratio of actual energy generated in a day to the energy generated if the system works $24 \mathrm{~h}$ a day, as Equation (1) and Equation (2)

$$
C U F=\frac{\text { Annual Yield }}{15.2 \mathrm{MW} \times 24 \mathrm{~h} \times 365 \mathrm{~d}} \times 100=\frac{22162 \mathrm{MWh}}{15.2 \mathrm{MW} \times 24 \mathrm{~h} \times 365 \mathrm{~d}} \times 100=16.64 \%
$$


CUF (Equation 2) of the SPV plant under study is $16.64 \%$. CUF is dependent on the location as GHI and panel efficiencies play a major role in determining it. The average CUF of SPV system located in Iran, where highest capacity factor was found at Bushier and lower at Anzali, i.e., 26.1 \% and $16.5 \%$, respectively [10]. A solar plant located in Navrongo, in the northern part of Ghana, has an average monthly capacity factor in the range of $13.9 \%$ in August and $18.2 \%$ in October [11].

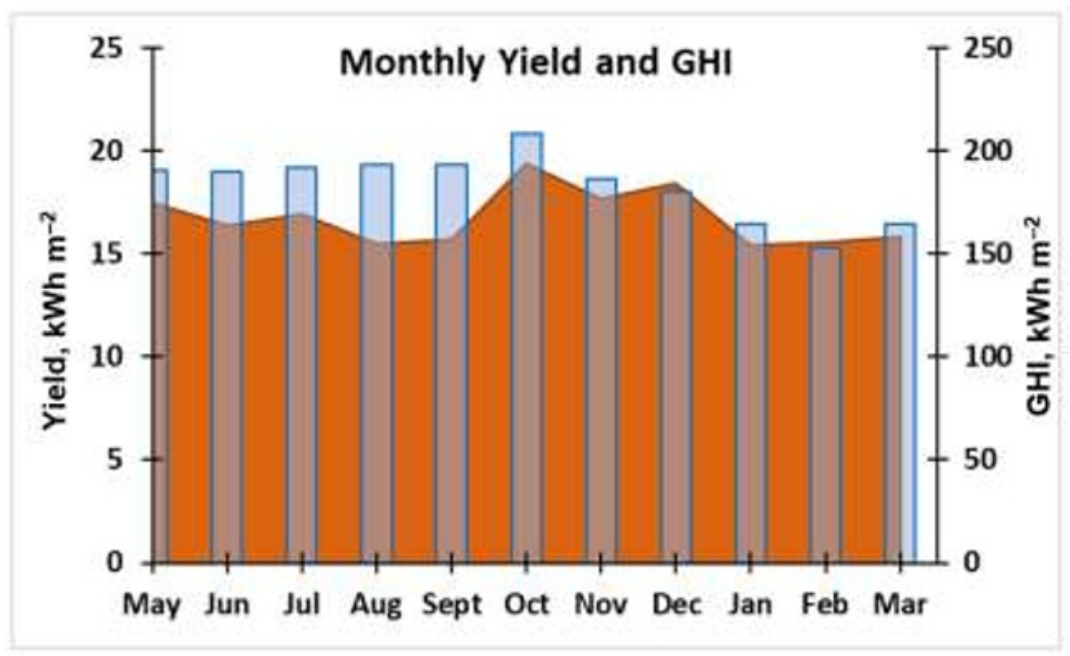

Fig. 2. Monthly yield and GHI for the year. The columns refer to the monthly yield and the stacked area is the GHI.

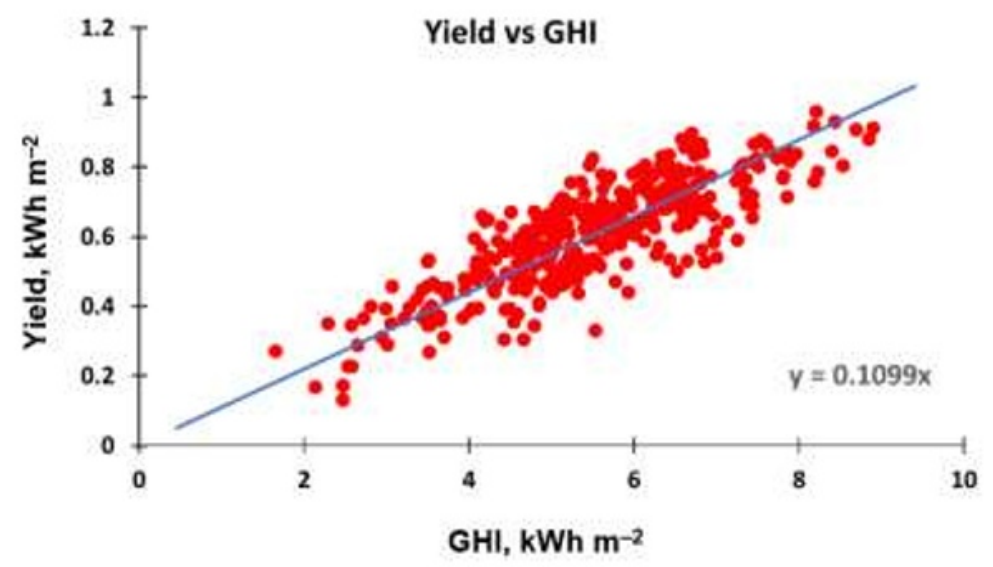

Fig. 3. Daily yield as a function of GHI, the solid line is the linear fit.

\subsection{Climatic condition that affect the SPV plant yield}

\subsubsection{Humidity}

Scattering and reflection of radiation occur from the surface of water droplets in addition to the absorption. Water has very strong absorption bands in the near infrared region. The 
humidity in the atmosphere affects the GHI that falls on SPV modules. According to a study by Panjwani and Narejo [12], for an increase in humidity of $25 \%$, the yield from the solar panel dropped by close to $30 \%$. The average humidity $(\mathrm{H})$, as measured at the SPV plant under study, in winter was $\sim 68 \%$ and in summer $\sim 58 \%$. This seasonal variation in $\mathrm{H}$, in addition to the intraday variations due to the presence of microclimate in the island, affects the yield from SPV system accordingly. As shown in Figure 4, Yield decreases at a rate of $37.5 \%$ with increase in $\mathrm{H}$ displaying a strong correlation between these two factors.

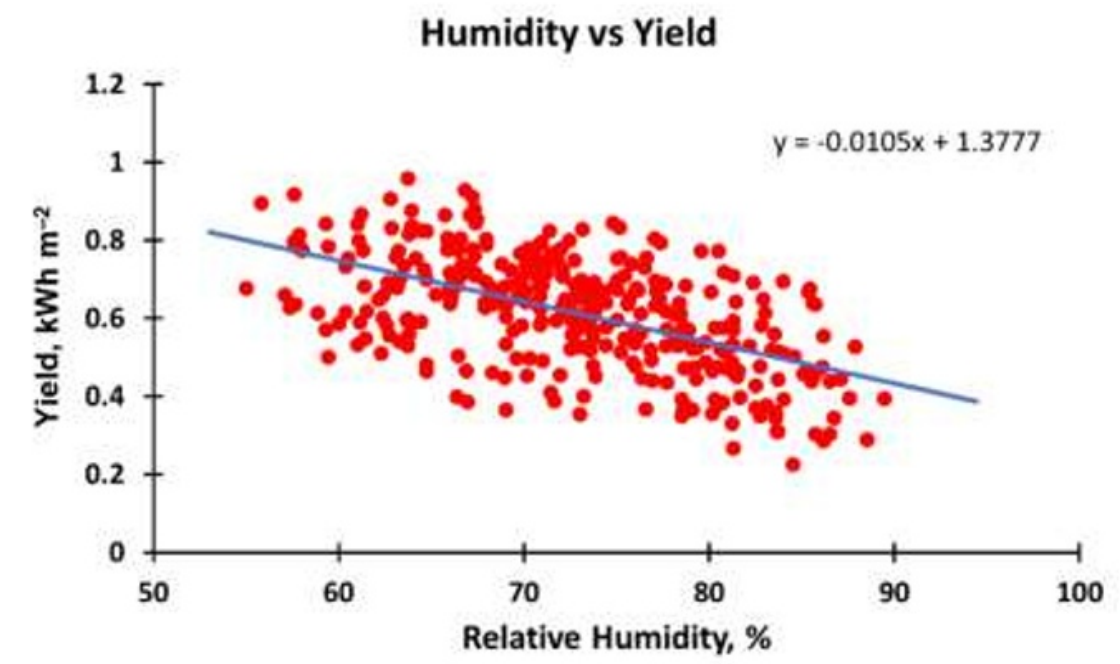

Fig. 4. Variation of yield with relative humidity, the solid line is the linear fit.

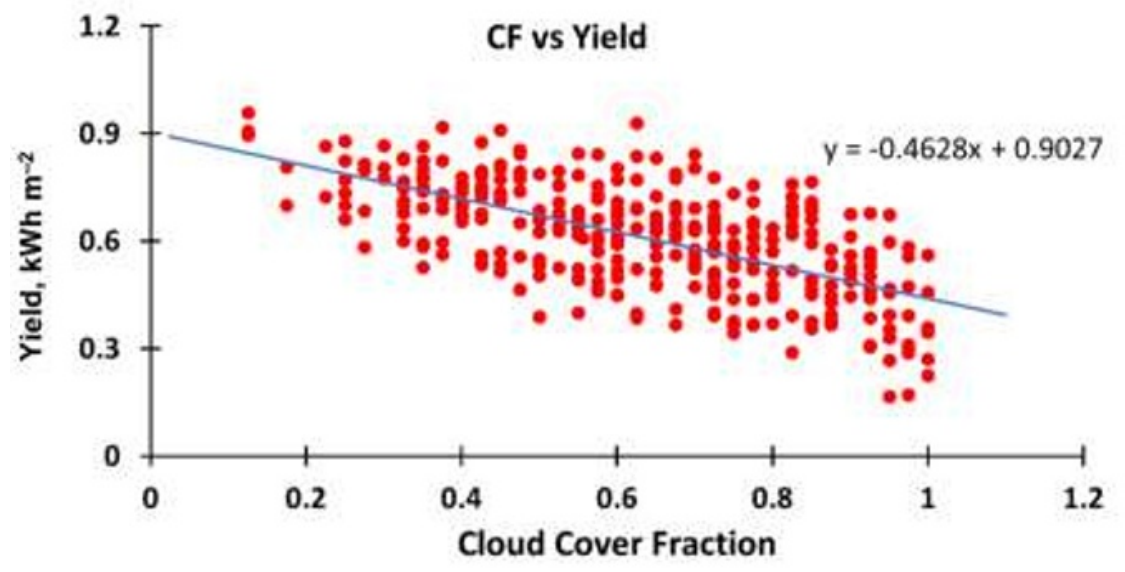

Fig. 5. Variation of yield with cloud cover fraction, the solid line is the linear fit.

\subsubsection{Cloud cover fraction (CF)}

Cloud cover refers to the fraction of the sky obscured by clouds when observed from a location. It is estimated that $20 \%$ of solar radiation are reflected by the clouds and therefore this factor is crucial while selecting a site to install a solar plant. The role of clouds in climate is still not well understood; they have two opposite effects. On the one hand they tend to cool the climate by reflecting short-wave solar radiation back into space, and on the 
other to warm the climate by trapping the long-wave radiation emitted from the Earth's surface. The simple equations to calculate the effect of Cloud cover fraction on incident solar radiation are insufficient to explain radiation loss in the atmosphere [13].

Daily average CF data are available from Mauritius Meteorological Services. Cloud cover is measured in Okta and is an integer between 0 to 8 . If there is no cover, the value is nil. If the sky is totally covered by cloud, the value is 8 . If $50 \%$ of the total slay has clouds, the value is $4(4 / 8: 50 \%)$. The $\mathrm{CF}_{\mathrm{d}}$ thus obtained is plotted against the yield per unit area (Y) of a day from the SPV system in Figure5. As CF increases, Yield decreases at a rate of about $50 \%$ indicating a strong correlation.

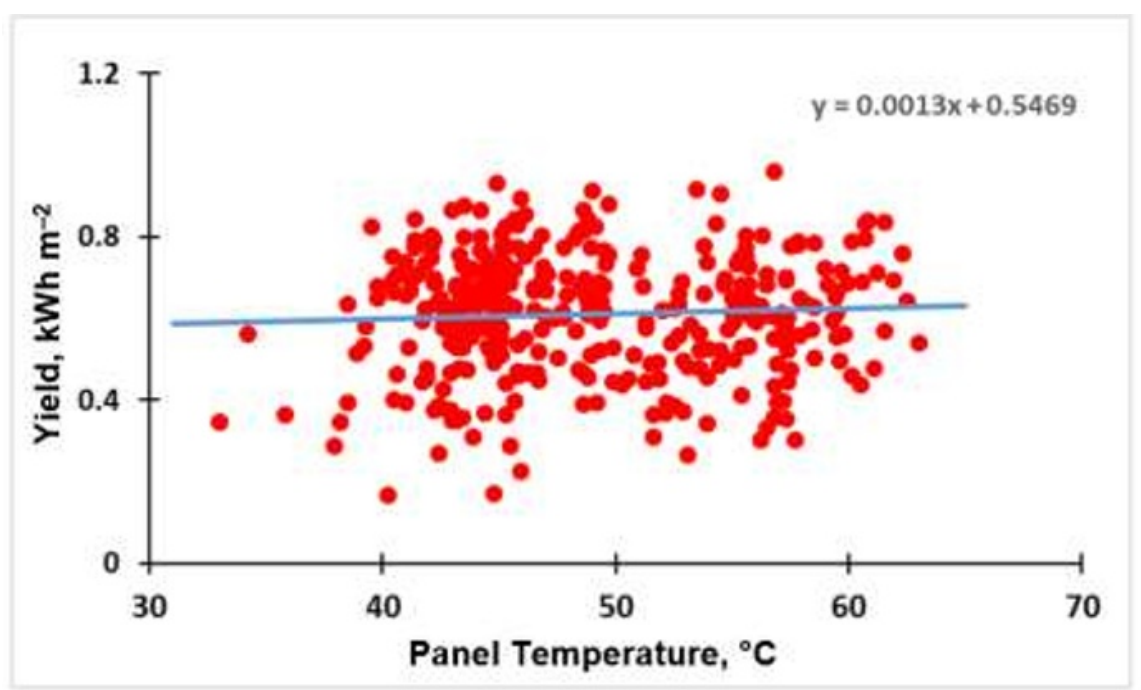

Fig. 6. Yield is plotted as a function of maximum temperature of the SPV panel, the solid line is the linear fit of the data.

\subsubsection{Panel temperature:}

One of the major challenges for developers and users of SPV plants is the overheating of panels due to high solar radiation and higher ambient temperatures. Increase in temperature of panels decreases their efficiency leading to lower power output from the SPV panels [14]. This is because the open circuit voltage decreases linearly with increase in panel temperature. Solar modules perform comparatively well at low temperatures [15].

The module operates over a wide range of temperatures throughout the year. This causes power output of the module to vary. For a module installed in a field, the module temperature at which the module attains maximum efficiency varies with seasons and the module efficiency is known to decrease with increase in module temperature $[14,16]$. However, the daily yield ( $\mathrm{Y}$ ) is the summation of power output of the day, which is dependent on solar insolation and module temperature. Figure 6 shows the variation of Yield corresponding to the maximum temperature attained by the panel in a day. On clear sunny days, the modules attain higher temperatures and the number of sunshine hours will also be more resulting in higher yield. At the location under consideration, variation in panel temperature has a smaller effect compared to other climatic parameters. This may be the reason for the large scatter in the data and poor correlation.

\subsubsection{Empirical equation:}

The yield from a SPV plant is collectively influenced by many climatic variables such as solar irradiance [17], albedo [18], number of sunshine hours [19], wind, humidity [20], precipitation, dust [21], etc. Presence of aerosols in the atmosphere can also scatter the 
incoming solar radiation. However, aerosol data was not available at the specific site under study, this effect is not considered. The above site-specific factors at a location are difficult to predict a priori with sufficient precision, more so in islands. Even within the island there can be differences at different regions due to the presence of microclimate as seen in Jeju island [22]. This makes predicting yield from a photovoltaic plant difficult.

As seen from Figure 4 and Figure 5 yield of the SPV system in Mauritius is dependent on relative humidity in the atmosphere and cloud cover fraction because of their effect on incoming solar radiation. These factors also have a seasonal variation; for instance, the relative humidity is high during summer season while during winters daily irradiance is low because of shorter days. To understand the influence of various factors on the overall output of a SPV system, a multivariate regression is carried out using the data from the system to come up with a consolidated expression, which is of the form, in Equation (3):

$$
\text { Yield }=\mathrm{K}+\alpha \mathrm{V}_{1}+\beta \mathrm{V}_{2}+\gamma \mathrm{V}_{3}+\delta \mathrm{V}_{4}
$$

where $\mathrm{K}, \alpha, \beta, \gamma$ and $\delta$ are constants and $\mathrm{V}_{1}, \mathrm{~V}_{2}, \mathrm{~V}_{3}$ and $\mathrm{V}_{4}$ are the variables. The variable inputs for the regression are daily Yield (Y), Relative humidity $(\mathrm{H})$, daily extraterrestrial radiation (ETR) at the latitude/longitude of the location, Cloud cover factor $(\mathrm{CF})$ and maximum panel temperature(T). ETR at the location under study was used instead of GHI because ETR calculations are accurate and can be computed easily in advance. Data from May 2017 to March 2018 were used and the regression equation obtained in Equation (4):

$$
\mathrm{Y}=1.2653-0.00429 \times \mathrm{ETR}-0.006850 \times \mathrm{H}-0.2844 \times \mathrm{CF}+0.00120 \times \mathrm{T}
$$

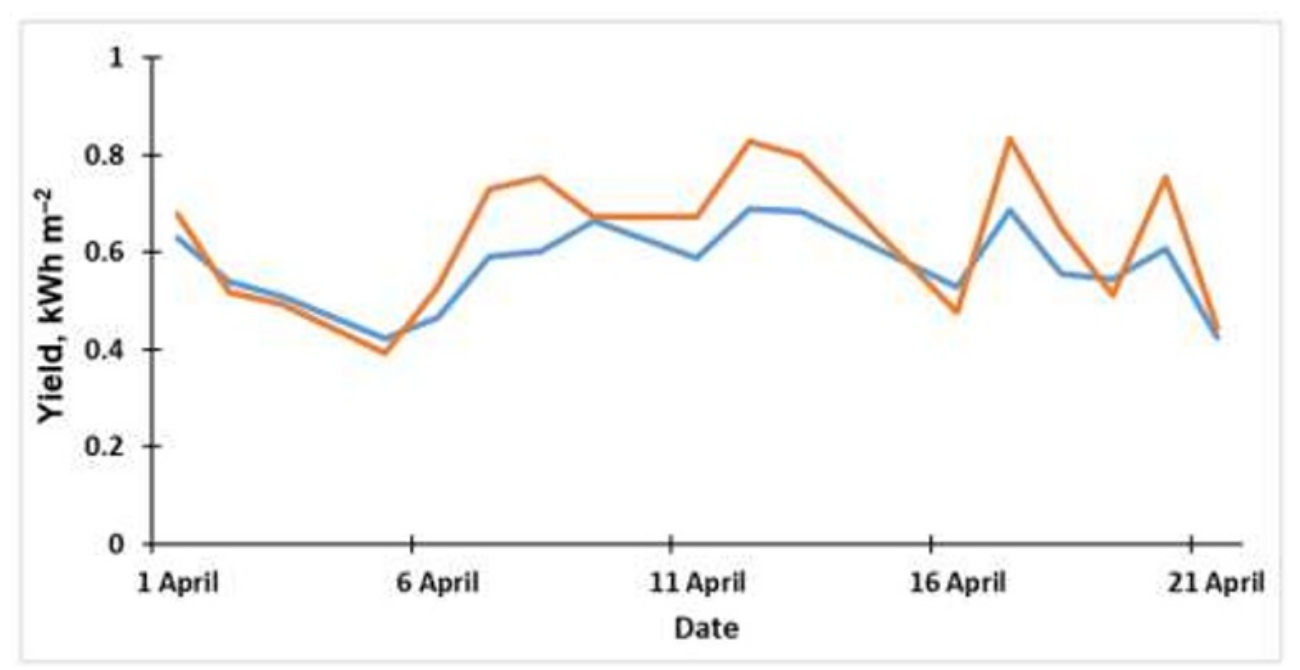

Fig. 6. Measured (orange line) and calculated (blue line) Yield for 3 wk in April 2018

Three more weeks data in April 2018, which were outside the data used for regression, became available and were used for validating Equation 4. However, Figure 7 shows the comparison of the computed yield for these days with the measured yield. Deviation from this model for most of these days is under $15 \%$ with $4 \mathrm{~d}$ under $20 \%$ indicating that the Equation 4 holds good. The large error is mostly for a few days with low GHI due to extreme weather conditions like high $\mathrm{CF}$ or $\mathrm{H}$. Almost all the countries around the world have weather forecasting systems that can predict the atmospheric conditions for about $48 \mathrm{~h}$ 
quite precisely. Many models have also been developed for forecasting multilevel CF [23, 24], solar radiation [25], ambient temperature and humidity [26]. Most of the countries, have weather forecasts available on the public domain, which are normally precise and reliable. Thus, by analyzing data from one SPV installation in a location and deriving an empirical equation of this type, it is possible to predict the yield from all other SPV systems in that location in advance. If the energy conversion efficiencies of SPV panels in different plants are different, a multiplication factor of ratio of the test panel efficiency and the measured panel efficiency must be applied to the yield calculated from Equation 4.

It is not common to measure the panel temperature in most of the SPV plants. On one system if module temperature data are collected, a relationship between maximum panel temperature (T) and daily average ambient temperature can be derived for the location that can be used for prediction. For the present location, $\mathrm{T}=1.093 \times \mathrm{T}$ (ambient daily avg) +22.983 relation fitted the data and with these calculated $\mathrm{T}$, all calculated yield were within $15 \%$ error except for $4 \mathrm{~d}$ where there was a deviation in the range of $15 \%$ to $19 \%$.

With such models that can predict the yield from an SPV plant a priori, it is possible to tune the polluting sources of electricity generation to just the required level when multiple resources are used in the grid. Thus, if the weather prediction for a day is with certain average ambient temperature, specific amount of humidity and CF, the yield from all the SPV plants in that location can be predicted. Based on the weather prediction, even $24 \mathrm{~h}$ in advance, enough usage of fossil fuel can be avoided because the term $b$ in Equation (1) would be known. There have been many models [27, 28] to predict power that can be generated from a wind turbine and hence the term $c$ in Equation (1) is also known and the terms a and $d$ can be fine-tuned amounting to minimum level of usage of thermal power plants using fossil fuels.

\section{Conclusion}

Power management in islands has many challenges as most of them do not have their own coal mines or oil wells. All the fossil fuel resources are transported and used on these islands leading to pollution of the pristine locations. Many of the islands are opting for renewable energy resources to generate electricity, as it is available in plenty on the location itself. In this paper, data from a 15.2 MW SPV plant in the island nation Mauritius is analyzed. Meteorological data for the duration of study is also considered. Correlations are drawn between the daily yield from the SPV plant and the meteorological parameters like cloud cover fraction and relative humidity. It is observed that the yield from the SPV plant decreases linearly with increase in humidity and CF. The panel temperature did not significantly influence the yield. An empirical model is developed based on the performance of the SPV plant and the climatic parameters at the location to predict the yield from the plant for future. With this prediction, electricity generation from fossil fuel fired thermal plants can be minimized to control the pollution on the islands. For most of the days, the model provides a less than $15 \%$ deviation from the measured values and for a few days with randomly changing weather or extreme weather conditions, it is in the range of $15 \%$ to $19 \%$. The accuracy of this model is dependent on the precision of forecast data available and weather conditions that are favorable for solar power generation.

\section{References}

1. Statistics Mauritius, Energy and Water Statistics - 2017, [Online] from: http://statsmauritius.govmu.org/English/Publications/Documents/2018/EI1386/Energy Yr17.pdf (2018). (Accessed on 10 September 2019). 
2. R. Bryce, I.L. Carreño, A. Kumler, B. Hodge, B. Roberts, C.B. Martinez-Anido, Solar Energy 67:61-75(2018).

https://doi.org/10.1016/j.solener.2018.03.085

3. S. Selosse, S. Garabedian, O. Ricci, N. Maïzi, Renewable and Sustainable Energy Reviews 89:99-105(2018)

https://doi.org/10.1016/j.rser.2018.03.013

4. D. Surroop, P. Raghoo, Renewable and Sustainable Energy Reviews 88:176183(2018).

https://doi.org/10.1016/j.rser.2018.02.024

5. A. Khoodaruth, V. Oree, M.K. Elahee, W.W. Clark II, Utilities Policy 44:38-49 (2017). https://doi.org/10.1016/j.jup.2016.12.001

6. B. Verhelst, D. Caes, L. Vandevelde, J. Desmet, Prediction of yield of solar modules as a function of technological and climatic parameters, IEEE International Conference on Clean Electrical Power, (Alghero, Italy, 2013). p. 1-6. https://doi.org/10.1109/ICCEP.2013.6586956

7. S.M. Vasisht, S.K. Ramasesha, Clean Techn Environ Policy 19:279-286(2017). https://doi.org/10.1007/s10098-016-1199-7

8. M.K. Mann, P.L. Spath, Clean Prod. Processes 3:81-91(2001). https://doi.org/10.1007/s100980100109

9. Energy Education, https://energyeducation.ca/encyclopedia/Diesel_generator (Visited on Sept. 19, 2019)

10. SM. Besarati, R.V. Padilla, D.Y. Goswami, E. Stefanakos, Renew. Energy, 53:193199(2013). https://doi.org/10.1016/j.renene.2012.11.012

11. L.D. Mensah, J.O. Yamoah, M.S. Adaramola, Energy for Sustainable Development 48:82-87(2018). https://doi.org/10.1016/j.esd.2018.11.003

12. M.K. Panjwani, G.B. Narejo, International Journal of Engineering Research and General Science, 2:499-503(2014). http://ijergs.org/files/documents/EFFECT-61.pdf

13. T. Molg, N.J. Cullen, G. Kaser, Journal of Glaciology 55:292-302(2008). https://doi.org/10.3189/002214309788608822

14. M.S. Vasisht, J. Srinivasan, S.K. Ramasesha, Solar Energy 131:39-46(2016). https://doi.org/10.1016/j.solener.2016.02.013

15. C. Schwingshackl, M. Petittaa, J.E. Wagner, G. Belluardo, D. Moser, M. Castelli, M. Zebisch, A. Tetzlaff, Energy Procedia, 40:77-86(2013). https://doi.org/10.1016/j.egypro.2013.08.010

16. G.M Tina, S. Scorfani, The 14th IEEE Mediterranean Electrotechnical Conference, 2008, Ajaccio, France, pp. 585-590(2008). https://doi.org/10.1109/MELCON.2008.4618498

17. T.V. Ramachandra, B.V. Shruthi, Renewable and Sustainable Energy Reviews 11:1460-1480(2007). https://doi.org/10.1016/j.rser.2005.12.002

18. R. Andrews, J.M. Pearce, Solar Energy 91:233-241(2013). https://doi.org/10.1016/j.solener.2013.01.030

19. R. Singh, R. Banerjee, Solar Energy 115:589-602(2015). https://doi.org/10.1016/j.solener.2015.03.016

20. S. Mekhilef, R. Saidur, M. Kamalisarvestani, Renewable and Sustainable Energy Reviews 16:2920-2925(2012). https://doi.org/10.1016/j.rser.2012.02.012 
21. Z.A. Darwish, H.A. Kazem, K. Sopian, M.A.A. Goul, H. Alawadhi, Renewable and Sustainable Energy Reviews 41:735-744(2015).

https://doi.org/10.1016/j.rser.2014.08.068

22. S.W. Kang, H. Yoon, S. Kim, A. Baatarbileg, J. Sakong and G. Lee, 5th International Conference on Renewable Energy: Generation and Applications (ICREGA), pg 52-55 (2018).

https://doi.org/10.1109/ICREGA.2018.8337571

23. A.S.M.B. Shah, H. Yokoyama, N. Kakimoto, IEEE Transactions on Sustainable Energy 6,2:474-481(2015).

https://doi.org/10.1109/TSTE.2014.2383398

24. C. Paoli, C. Voyant, M. Muselli, M.L. Nivet, Solar Energy 84:2146-2160(2010). https://doi.org/10.1016/j.solener.2010.08.011

25. S. Pelland, G. Galanis, G. Kallos, Progress in Photovoltaic: Research and Applications 21:284-296(2011).

https://doi.org/10.1002/pip.1180

26. P. Kumar, S.P. Ojha, R. Singh, C.M. Kishtawal, P.K. Pal, Theoritical and Applied Climatology 122:1-9(2015). https://doi.org/10.1007/s00704-015-1607-7

27. A.K. Fard, A. Khosravi, S. Nahavandi, IEEE Transactions of Power Systems 31,1:1826(2016).

https://doi.org/10.1109/TPWRS.2015.2393880

28. Y. Zhang, J. Yang, K. Wang, Z. Wang, Energies 8,1:475-489(2015).

https://doi.org/10.3390/en8010475 